\title{
Floração de algas na Cavidade Natural Lagoa Misteriosa (MS 043), Jardim, MS, Brasil: uma análise integrada de dados físico- químicos, biológicos e climatológicos
}

\author{
Floración de las algas en la Cavidad Natural Laguna Misteriosa \\ (MS 043), Jardim, MS, Brasil: un análisis integrado de datos \\ físico-químicos, biológicos y climatológicos
}

\section{Algal bloom in Natural Cavity Lagoa Misteriosa (MS 043), Jardim, MS, Brazil: an integrated analysis of physical-chemical, biological, and climatological features}

\author{
Sandro Marcelo Scheffler \\ schefflersm@mn.ufrj.br \\ Universidade Federal do Rio de Janeiro, UFRJ, Rio de Janeiro, RJ \\ William Marcos da Silva \\ wmsilvax@ig.com.br \\ Universidade Federal do Mato Grosso do Sul, UFMS, Campus Pantanal, Corumbá, MS \\ Angela Pellin \\ angela@ipe.org.br \\ Instituto de Pesquisas Ecológicas, IPÊ, Nazaré Paulista, SP \\ Samuel Duleba \\ samuelduleba@gmail.com \\ Instituto de Pesquisas Ecológicas, IPÊ, Nazaré Paulista, SP \\ Andrea Pellin \\ andreapellin@ipe.org.br \\ Instituto de Pesquisas Ecológicas, IPÊ, Nazaré Paulista, SP
}

Resumo: A Cavidade Natural Lagoa Misteriosa é a caverna inundada mais profunda do Brasil, com mais de $220 \mathrm{~m}$ de coluna d'água. Suas características geológicas únicas, aliadas à sua biodiversidade, beleza cênica e ciclos anuais de floração de algas, conferem a este ecossistema um status único no Brasil. Entre os anos de 2005 e 2009 foram realizados uma série de estudos com intuito de embasar um plano de manejo para a cavidade, envolvendo coletas de dados do nível da água da lagoa, pluviometria, temperatura, análises físico-químicas e biológicas da água, visibilidade, entre outros. A partir destes estudos foi possível formular um modelo que explica a sazonalidade da floração de algas responsáveis pelo turvamento das águas durante o verão. Os resultados demonstraram que a pluviosidade e quedas bruscas de temperatura seriam os principais agentes que atuam sobre o bloom de algas, relacionado ao carreamento de nutrientes e aumento da produção primária.

Palavras-chave: Caverna calcária, Serra da Bodoquena, Mato Grosso do Sul. 
Resumen: La cavidad natural Laguna Misteriosa es la cueva inundada más profunda de Brasil con más de 220 metros de columna de agua. Sus características geológicas únicas, aliadas a su biodiversidad, belleza escénica y ciclos anuales de floración de algas, confieren a este ecosistema un estatus único en Brasil. Entre 2005 y 2009, se llevaron a cabo una serie de estudios para respaldar un plan de gestión de cavidades que incluye la recopilación de datos del nivel del agua del estanque, lluvia, temperatura, análisis fisicoquímicos y biológicos del agua, visibilidad, entre otros. A partir de estos estudios, fue posible formular un modelo que explica la estacionalidad de las floraciones de algas responsables de la turbidez de las aguas durante el verano. Los resultados mostraron que la lluvia y quedas bruscas de temperatura serían los principales agentes que actúan en la floración de las algas, en relación con el arrastre de nutrientes y aumento de la producción primaria.

Palavras clave: Cueva calcárea, Serra da Bodoquena, Mato Grosso do Sul.

Abstract: Natural cavity Lagoa Misteriosa is the deeper flooded cave in Brazil, with more than $220 \mathrm{~m}$ of the water column. Its unique geological features, allied to its biodiversity, scenic beauty, and annual cycles of algal bloom, give this ecosystem a unique status in Brazil. Between 2005 and 2009, a series of studies were carried out to support a cavity management plan involving data collection of pond water level, rainfall, temperature, physicochemical and biological analyses of water, visibility among others. From these studies, it was possible to formulate a model that explains the seasonality of algal blooms responsible for the turbidity of waters during the summer. The results showed that rainfall and temperature fall are the main agents acting in the algae bloom, related to nutrients carryover and increased primary production.

Keywords: Limestone Cave, Serra da Bodoquena, Mato Grosso do Sul.

\section{INTRODUÇÃO}

A Cavidade Natural Lagoa Misteriosa (MS 043) localiza-se na Fazenda Lagoa Misteriosa, no município de Jardim, sudoeste do estado do Mato Grosso do Sul. O acesso é feito pela BR 267, Jardim-Porto Murtinho, km 515. Integra o Carste da Serra da Bodoquena juntamente com outras 200 cavernas já registradas (SALLUN FILHO; KARMANN; LOBO, 2010), com grande variedade de habitats subterrâneos, incluindo sistemas de cavernas freáticas, submersas e secas (CORDEIRO; BORGHEZAN; TRAJANO, 2014).

Está situada na unidade morfológica planície arenítica com dolinas da Província Espeleológica da Serra da Bodoquena (SALLUN FILHO; KARMANN, 2007a), onde calcários dolomíticos, provavelmente do Grupo Corumbá, passam a ser recobertos pelos arenitos permo-carboníferos da Formação Aquidauana. Esta região é uma área de recarga de aquífero e, conforme Sallun Filho e Karmann (2007b), é formada pelo desenvolvimento de um sistema cárstico subjacente, profundo, em ambiente freático. A Serra da Bodoquena é caracterizada por ser um local de alta diversidade de troglóbios na América do Sul (CORDEIRO; BORGHEZAN; TRAJANO, 2014).

A baixa densidade da rede hidrográfica na área, quando comparada com áreas adjacentes, principalmente aquelas situadas mais ao sul e leste, reforça a existência de uma drenagem subterrânea bem desenvolvida, mesmo em áreas recobertas pelo Arenito Aquidauana, devido ao espesso pacote de rochas calcárias situado abaixo de uma fina 
camada arenítica (FERNANDES; SCHEFFLER, 2009). Disso resulta que toda a região constitui um carste ainda ativo, no qual o processo de abertura das dolinas é muito rápido (LINO et al., 1984; SCHEFFLER, 2009a, b), sendo ainda comuns outras feições de relevo cárstico como morros residuais, cavernas, ressurgências e sumidouros.

Conforme Lino et al. (1984), a Lagoa Misteriosa é uma típica dolina de abatimento, inundada, que expõe paredes verticais escalonadas de calcário com aspecto marmóreo, permitindo em seu fundo o afloramento do lençol freático em forma de uma lagoa de aproximadamente $65 \times 24$ metros. Segundo Sallun Filho e Karman (2007b), apresenta 400 x 200 metros de eixo maior e menor e 75 metros de profundidade até o nível da lagoa. Seu grande desenvolvimento vertical a confere o título de caverna inundada mais profunda do país, com mais de 220 metros de coluna d'água (SBE, 2019). Na época em que foi realizada a topografia subaquática (BARROCO NETO, 2009) a área da superfície da lâmina d'água era de aproximadamente $900 \mathrm{~m}^{2}$. As duas entradas, que levam ao salão principal, estão situadas a aproximadamente 6 metros do nível da lagoa (variando conforme o nível do lençol freático) e apresentam área somada de aproximadamente $300 \mathrm{~m}^{2}$ (Fig. 1).

Trata-se de um corpo de água bastante profundo para os padrões de lagoas e lagos naturais brasileiros, que são, em sua maioria, mais rasos, com menos de 30 metros (TUNDISI; MATSUMURA-TUNDISI, 2008). Outra particularidade deste ambiente são as águas carbonatadas, típicas de regiões calcárias, que formam complexos entre o material em suspensão e os carbonatos dissolvidos que precipitam, tornando as águas muito cristalinas (FERNANDES; SCHEFFLER, 2009).

Segundo Amaral Filho (1989), o clima na região é termoxeroquimênico atenuado "Tropical Atenuado do Centro-Sul do Mato Grosso do Sul", com temperatura média do mês mais frio entre $15 \mathrm{oC}$ e $20 \mathrm{oC}$, com período de seca de três a quatro meses e precipitações entre 1.200 a $1.500 \mathrm{~mm}$ anuais. Apresenta índice hídrico de 20 a 40 e moderada deficiência de água no inverno, sendo que a evapotranspiração anual é superior a 1.140 mm (MENDES et al., 2004). 
Figura 1. Desenho esquemático da Cavidade Natural Lagoa Misteriosa.

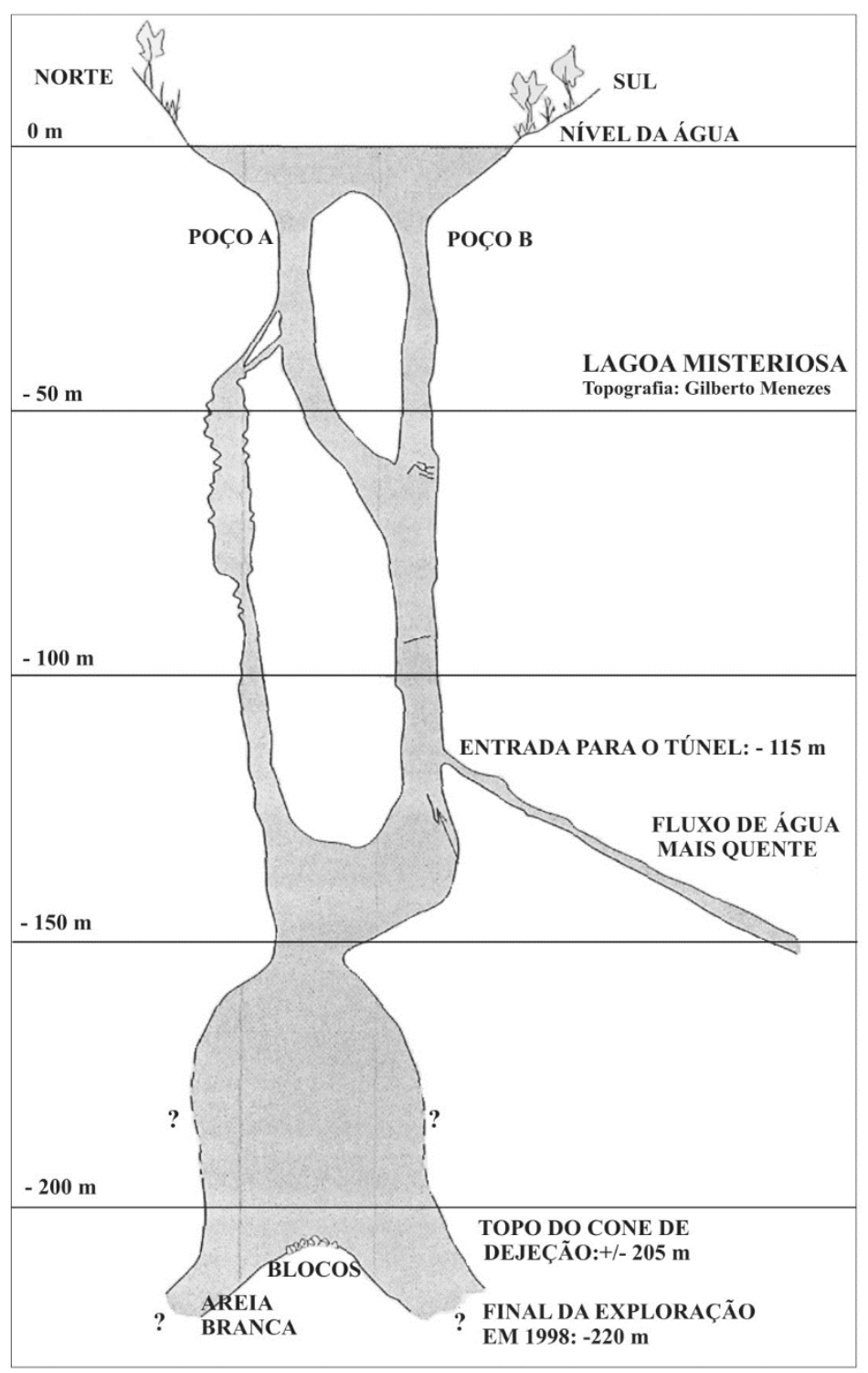

Fonte: modificado de Oliveira (2001).

A fauna subaquática da lagoa é abundante mas relativamente pobre em espécies, com o registro de duas espécies de peixes, lambaris, da Subfamília Tetragonopterinae. Cordeiro, Borghezan e Trajano (2014) classificam este lambari em duas espécies: Astianax bimaculatus Linnaeus, 1758 e Astianax lineatus Perugia, 1891, além de um muçum da Família Synbranchidae - Synbranchus aff. marmoratus Bloch, 1795, que ocorre na zona fótica; o crustáceo Spelaeogriphacea Potiicoara brasiliensis Pires, 1987, encontrado na fenda lateral do duto A, totalmente escura, e em grandes profundidades; o cnidário Craspedacusta sowerbii Lankester, 1880, que aparece em sua forma livre-natante normalmente durante um período de três a quatro semanas, entre março e abril; além de diversas espécies pertencentes ao fito e zooplâncton (FERNANDES; SCHEFFLER, 2009). 
Chama a atenção a floração de algas que ocorre todos os anos na Lagoa Misteriosa. Na estação seca, aproximadamente entre meados de abril e início de outubro, as águas da lagoa estão cristalinas com tonalidade azul e visibilidade que pode chegar a mais de 40 metros (Fig. 2). No entanto, durante a estação chuvosa as águas assumem uma tonalidade verde bastante intensa, com visibilidade reduzida, muitas vezes para menos de 2 metros. Segundo relatos de antigos moradores da área, a Lagoa Misteriosa começou a turvar nos meados da década de 1970, mas na época não era um fenômeno anual. Ainda segundo os moradores, a atividade predominante no entorno sempre foi a pecuária, no entanto pastagens exóticas passam a ser implantadas a partir de 1982 (FERNANDES; SCHEFFLER, 2009).

Figura 2. (a) Lagoa Misteriosa com suas águas cristalinas em 24/04/2006; (b) Lagoa Misteriosa com suas águas cristalinas em 27/04/2006; (c) e (d) Lagoa Misteriosa com suas águas turvas em 10/10/2006.

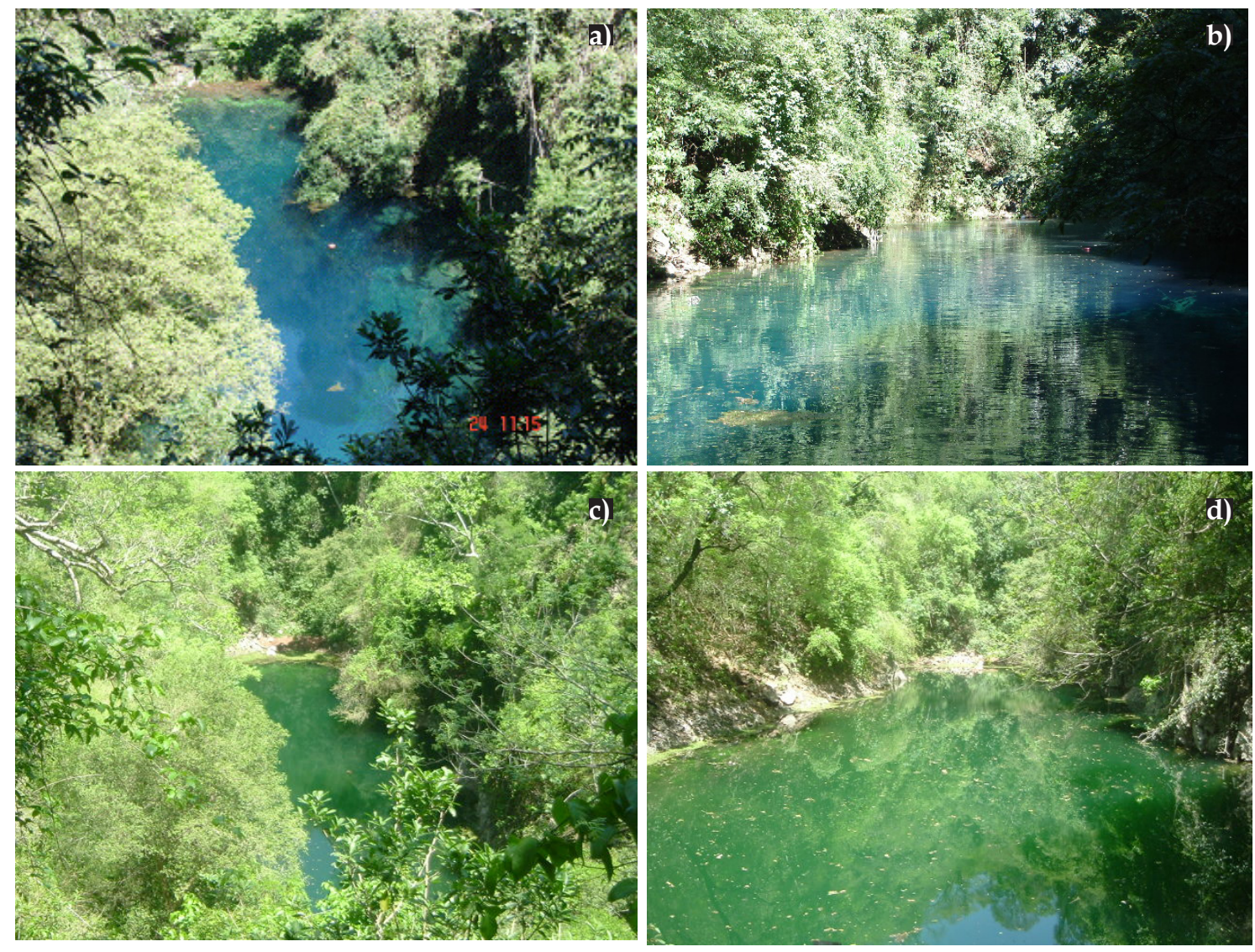

Fonte: arquivo pessoal dos autores.

No Brasil, sistemas de dolinas inundadas são pouco estudados, estando ausentes das principais referências sobre limnologia do país, tais como Kleerekoper (1944), Esteves (1998), Matsumura-Tundisi e Tundisi (1995) e Tundisi e Matsumura-Tundisi (2008). Isso destaca a necessidade de estudos para entender esses ecossistemas. Isso é ainda mais relevante no caso da Lagoa Misteriosa, onde as características geológicas únicas do sistema cárstico relacionado a esta dolina, aliadas à sua biodiversidade, beleza cênica e ciclos anuais de floração de algas, conferem a este ecossistema um status único no Brasil. 
No ano de 2005 teve início a elaboração de uma série de estudos, com coletas de dados secundários e diagnósticos em campo do meio físico e biológico, com intuito de embasar um plano de manejo para visitação espeleoturística, finalizado no ano de 2009 (FERNANDES; SCHEFFLER, 2009). Estes estudos ampliaram o conhecimento sobre a biodiversidade do local e forneceram informações sobre o meio físico que contribuíram para o entendimento do funcionamento dos sistemas cársticos na região. A partir destes estudos foi possível formular um modelo teórico explicativo da sazonalidade da floração de algas responsável pelo turvamento das águas da cavidade, apresentado neste artigo.

\section{MATERIAL E MÉTODOS}

A coleta dos dados físicos e químicos da água da Lagoa Misteriosa foi realizada mensalmente entre setembro de 2005 e fevereiro de 2009, em amostras coletadas no centro do espelho d'água, na zona limnética, a uma profundidade entre 0,5 e 1 metro; a amostra para clorofila foi coletada apenas em 2008.. Os dados biológicos foram coletados durante o ano de 2008. As análises seguiram o recomendado pelo APHA Standard Methods for the Examination of Water and Wastewater 20th Edition e incluíram turbidez, nitrogênio total, fósforo total, demanda biológica de oxigênio (DBO), demanda química de oxigênio (DQO), oxigênio dissolvido (OD) e potencial de hidrogênio $(\mathrm{pH})$.

Outros dados também foram coletados entre 2005 e 2009 através de vistorias periódicas: condições climáticas (pluviometria, temperatura ambiente dentro e fora da dolina, temperatura da água na superfície e abaixo de 3 metros de profundidade), hidrológicas (visibilidade vertical e horizontal, incidência de luz na superfície, nível da água, sedimentos suspensos), além de registro fotográfico externo/subaquático e observações adicionais. A periodicidade das vistorias variava de acordo com as condições climáticas, sendo realizadas principalmente após as chuvas e frentes frias ou ainda intensificadas em data próxima a mudança observada no ciclo das algas.

Para obtenção da série histórica pluviométrica foram utilizados dados coletados entre os anos de 1994 e 1999 através de pluviômetro da sede da Fazenda Cabeceira do Prata, a qual dista aproximadamente 1,5 km a oeste da Lagoa Misteriosa. Para o ano 2000 foi empregada a média entre dois pluviômetros nesta fazenda, o da sede e outro na nascente do córrego Olho d'Água; em 2001 foi incluído um terceiro pluviômetro situado as margens do Rio da Prata, também no interior da fazenda. Entre 2002 e 2006 um quarto pluviômetro foi posicionado na entrada da fazenda e, finalmente, em 2007 foi acrescentado um quinto pluviômetro, posicionado na área da Fazenda Lagoa Misteriosa, a aproximadamente 1 $\mathrm{km}$ da dolina.

As medidas da variação do nível da lagoa foram realizadas de forma esporádica entre 2005 e 2006, porém a partir de 2007 estas observações foram feitas mensalmente com auxílio de uma régua posicionada no deque de entrada da lagoa. 


\section{RESULTADOS E DISCUSSÃO}

As médias anuais de chuva variaram entre 970 e 1.830 mm, mostrando uma variação na amplitude muito maior que a apresentada por Amaral Filho (1989) para esta região do estado. Muito marcante é a deficiência hídrica, principalmente entre maio a setembro, onde as chuvas acumuladas no período atingem apenas $200 \mathrm{~mm}$, com anos muito mais secos (Fig. 3).

Correlacionando os dados de pluviometria e a variação do nível d'água (Fig. 4a) pode-se observar que o nível da água da Lagoa Misteriosa responde de forma muito rápida às precipitações na área. O nível máximo anual é atingido normalmente no mês de março ou de abril, reflexo da maior concentração pluviométrica desta época do ano, principalmente dos meses de novembro, dezembro e janeiro. Estes dados demonstram que a recarga do lençol freático parece acontecer de forma muito rápida, sendo que as primeiras elevações do nível do lençol ocorrem aproximadamente de 15 dias a um mês após as primeiras fortes chuvas depois da estiagem.

Da mesma forma, o nível mínimo normalmente foi atingido no início do período das chuvas, sendo em setembro nos anos de 2005 e 2006, quando ocorreram fortes chuvas no final de setembro e início de outubro; em meados de novembro no ano de 2007, ano em que o período de estiagem foi mais prolongado e as chuvas começaram apenas na segunda metade de outubro; e no final de dezembro e início de janeiro em 2008, ano atípico em que este nível mais baixo atrasado talvez reflita um índice pluviométrico abaixo do normal e com poucas chuvas fortes nos meses de setembro, outubro e novembro (Fig. 3).

A medida da visibilidade horizontal da Lagoa Misteriosa (Fig. 4b) aponta para dois períodos bem marcantes, um com visibilidade extremamente alta de 45 metros, entre abril e setembro, na ausência da floração de algas, e outro com visibilidade muito baixa de menos de 5 metros, entre outubro a início de abril, quando está ocorrendo a floração de algas. Estes dados levaram Coelho (2009) a caracterizar a lagoa como um ambiente que apresenta um período oligotrófico por cerca de seis meses, com baixa produtividade e alta transparência da água, e um período mesotrófico a eutrófico nos outros seis meses, com alta produtividade e visibilidade baixa. A diminuição atípica da visibilidade em julho de 2009 deveu-se a forte chuva que carreou sedimentos para a lagoa, e não ao fenômeno de floração de algas.

Em mergulho realizado em dezembro de 2008 foi verificado que camada fitoplanctônica, densa, se concentra normalmente nos primeiros 5 a 7 metros próximos a superfície, podendo chegar até 10 metros de profundidade. Abaixo desta a água mantém a característica cristalina própria de ambientes cársticos, no entanto a visibilidade não é boa devido a interferência de entrada dos raios solares pela presença da biomassa. 
Figura 3. Índices pluviométricos da área de estudo ao longo de 2006, 2007 e 2008. As barras em verde correspondem a média de quatro pluviômetros diferentes, situados na sede, na porteira, na nascente do córrego Olho d'Água e no deque de desembarque do passeio Rio da Prata da Fazenda Cabeceira do Prata.

Índices pluviométricos - 2006

(a)

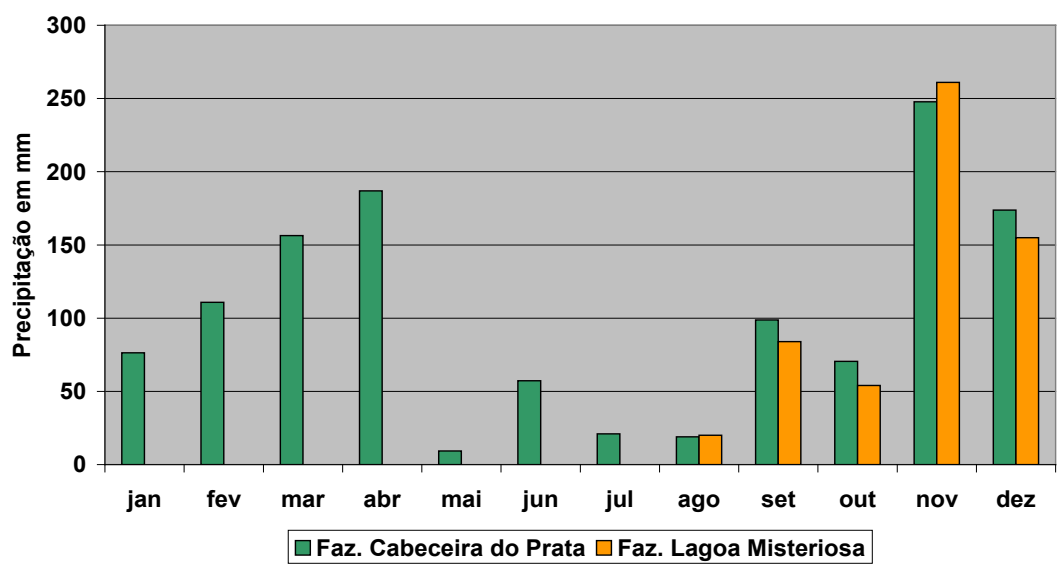

Índices pluviométricos - 2007

(b)

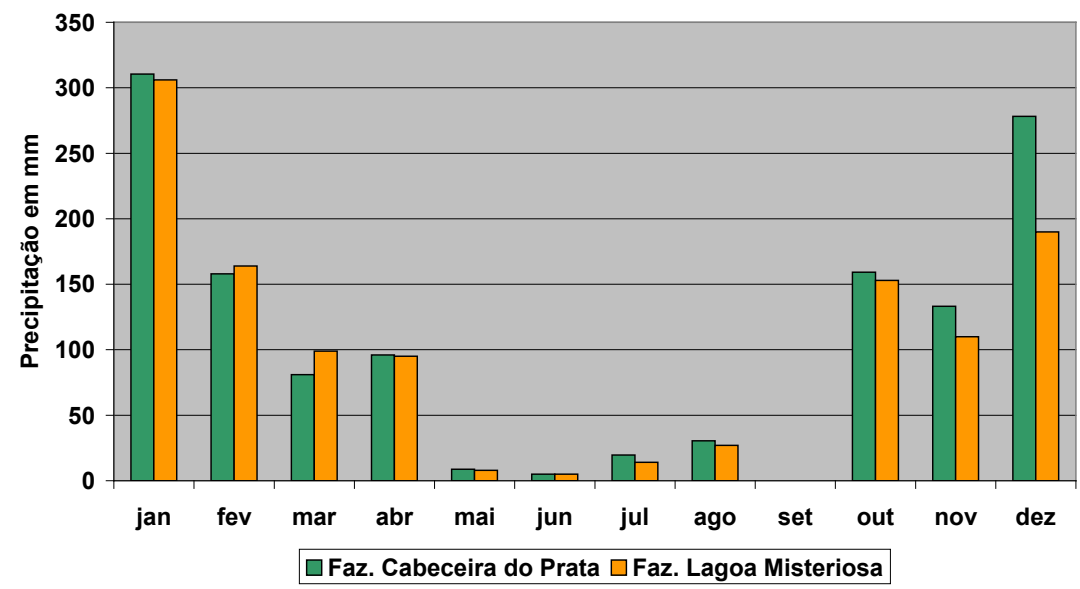

Índices pluviométricos - 2008

(c)

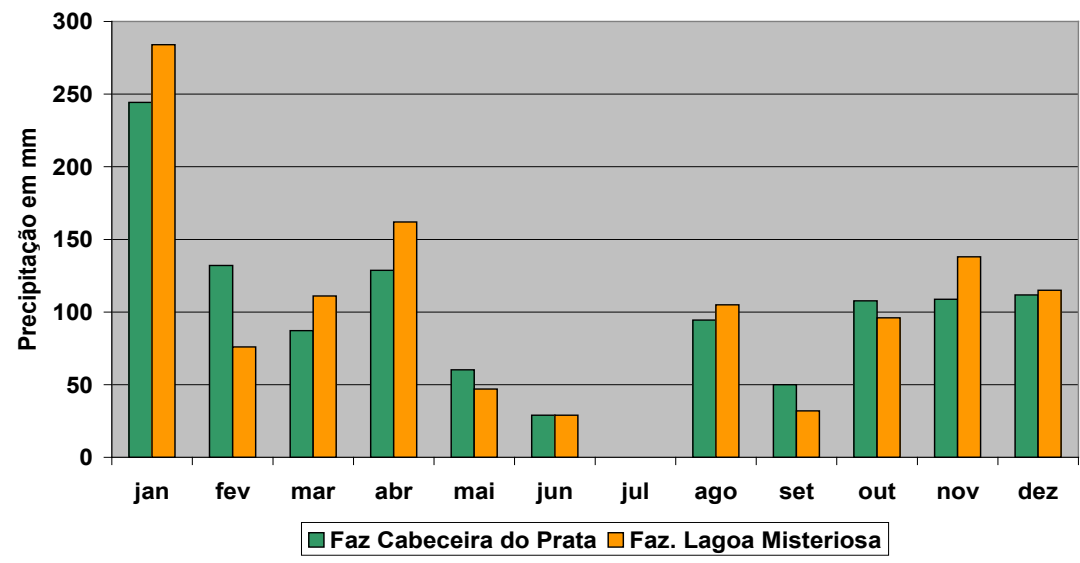

Fonte: os autores. 
Figura 4. Variação do nível d'água da lagoa de 2005 a 2008 (a). Visibilidade horizontal da lagoa nos anos de 2008 e 2009 (b).

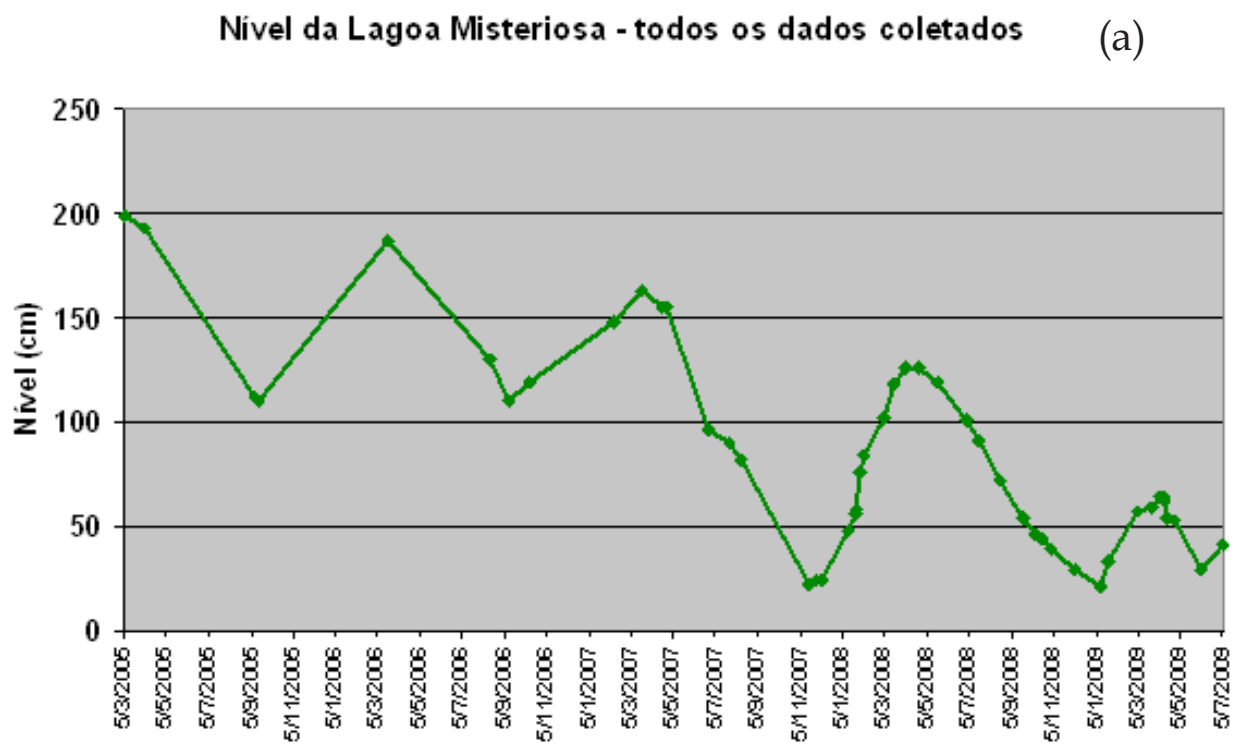

VISIBILIDADE DA LAGOA MISTERIOSA

(b)

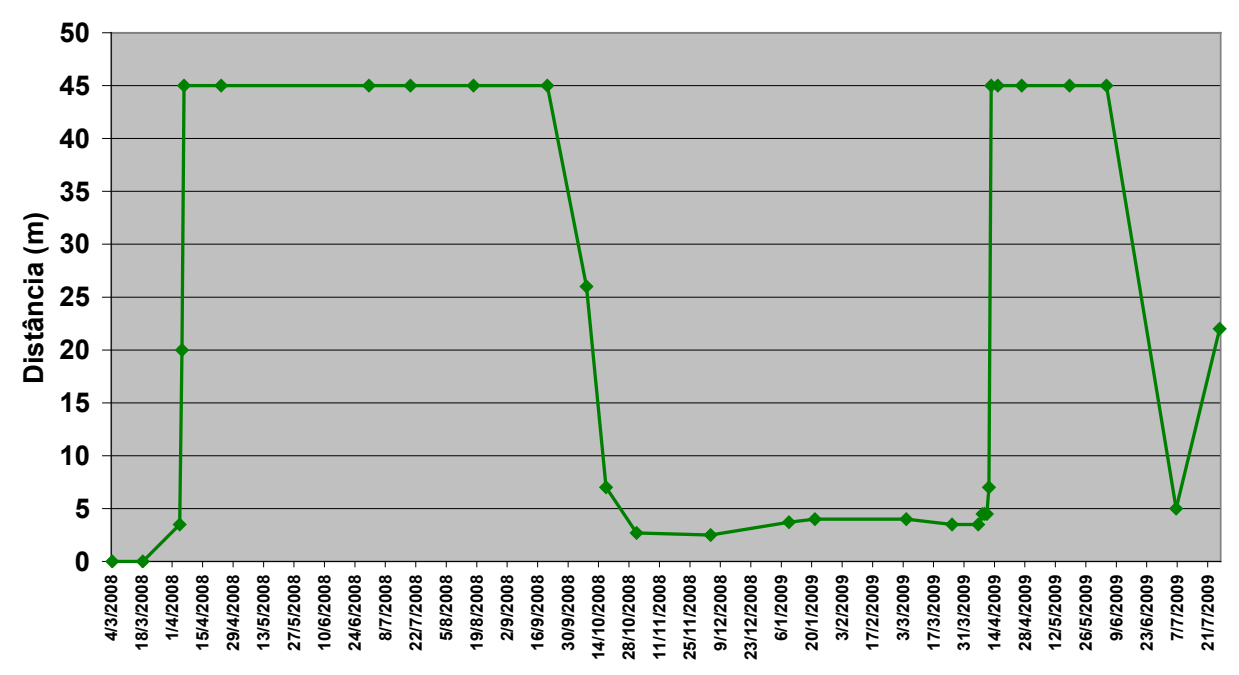

Fonte: os autores.

Através da análise das Figuras 5 e 6 fica claro que a principal causa da floração de algas, e consequente aumento da turbidez da água, é o aumento na quantidade de nitrogênio e fósforo totais na lagoa. Este aumento é coincidente com o início do período de chuvas, pois as águas pluviais carreiam sedimentos e substâncias químicas da área do entorno ocasionando um aporte de nutrientes para dentro da lagoa. No verão as concentrações destes elementos químicos são altas, podendo chegar a nove e quatorze vezes acima das concentrações do inverno de fósforo e nitrogênio, respectivamente.

No ano de 2005 a floração se deu a partir do início de outubro, com gradual turvamento da lagoa, após uma forte chuva de aproximadamente $150 \mathrm{~mm}$ em 24 de setembro 
e outras menores que ocorreram dia 1, 5 e 6 de outubro. Em 2006 o turvamento ocorreu no final de setembro e início de outubro após a chuva de aproximadamente $80 \mathrm{~mm}$ que ocorreu no dia 28 de setembro e outras menores nos dias 3 e 5 de outubro. Em 2007 o turvamento ocorreu entre os dias 20 e 25 de outubro após chuva de $46 \mathrm{~mm}$ no dia 19, e de $80 \mathrm{~mm}$ no dia 24. Já no ano de 2008 o turvamento ocorreu de forma mais gradual entre os dias 8 e 23 de outubro (Fig. 6), pois ocorreram apenas chuvas fracas (variando entre 7 e 28 $\mathrm{mm}$ ) em seis dias bem distribuídos ao longo do mês.

Figura 5. Variação de turbidez, nitrogênio e fósforo totais na água da lagoa entre 2005 e 2009.

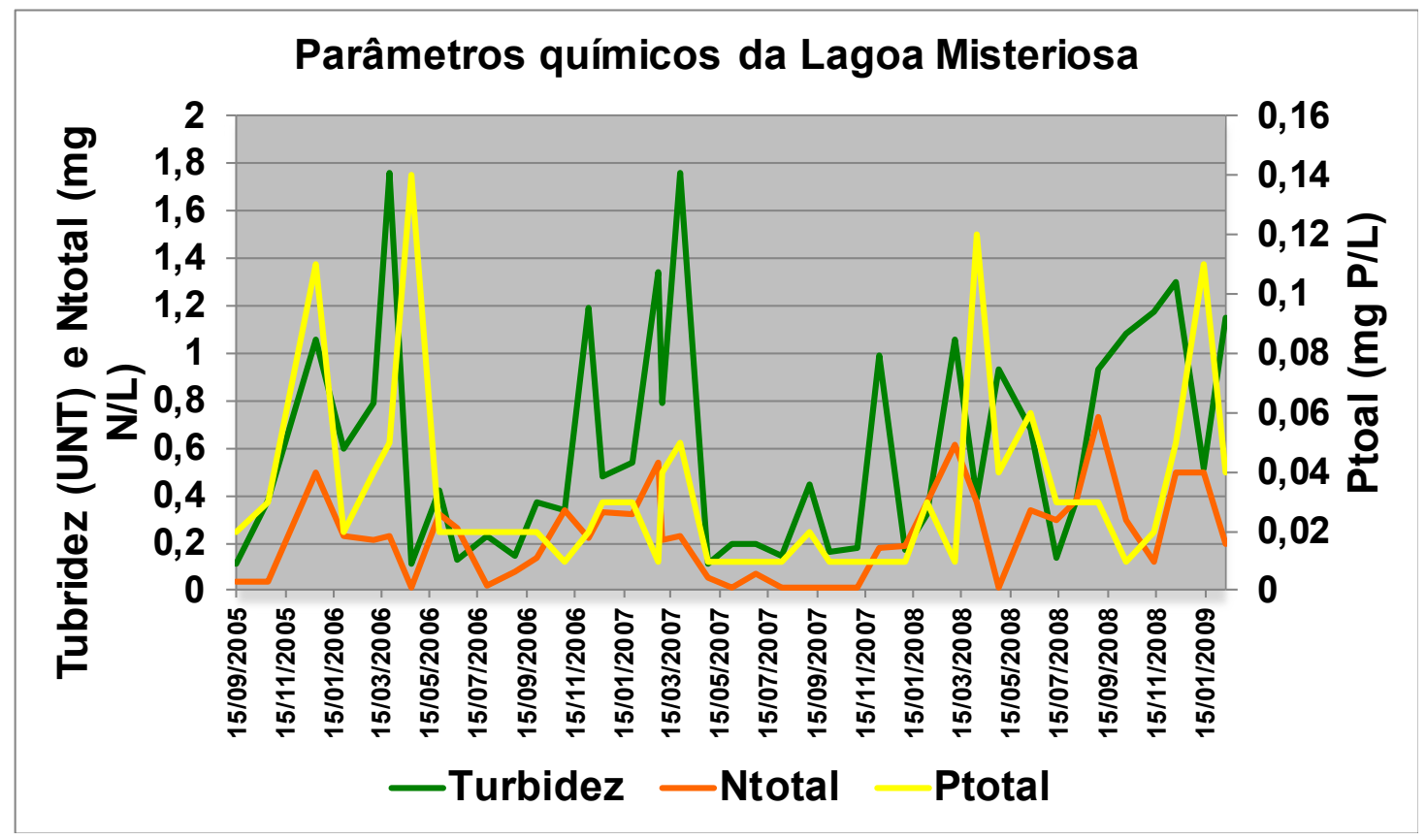

Nota: os valores de Fósforo total foram multiplicados por dois para adequação de escala. Fonte: os autores.

O ano de 2008 foi atípico pelo grande índice pluviométrico incomum em agosto; a ausência de floração neste inverno, apesar das altas concentrações de fósforo e nitrogênio observadas, corrobora que o fenômeno de floração de algas não é controlado apenas pelas concentrações destas substâncias, mas também por outros parâmetros sinergéticos como a incidência luminosa, pH e temperatura (RAVEN et al., 2001). Isto foi verificado na lagoa, já que no mês de agosto o sol incide apenas por cinco horas diárias sobre a superfície da água, enquanto em fevereiro esta incidência é de aproximadamente seis horas e meia diárias. Também ocorre um aumento na temperatura média da água, que nos dias mais frios pode chegar a $23^{\circ} \mathrm{C}$ e nos dias mais quentes a $26^{\circ} \mathrm{C}$. Nos dias em que houve acompanhamento durante um dia inteiro, a temperatura da água a 2 metros de profundidade não variou durante o período. Ocorre uma pequena variação, de no máximo $1^{\circ} \mathrm{C}$, na água da superfície em relação a água a 2 metros de profundidade devido a incidência dos raios solares. 
Figura 6. (a) Vista da lagoa no dia 08/10/2008 (15:30hs); (b) Apesar da visibilidade ainda ser de aproximadamente 30 metros, começa a aparecer uma camada de algas (aproximadamente $40 \mathrm{~cm}$ de espessura) na superfície da lâmina d'água; (c) Vista da lagoa no dia 17/10/2008: visibilidade vertical - $7 \mathrm{~m}$; visibilidade horizontal - $4 \mathrm{~m}$; (d) Vista da lagoa no dia 31/10/2008: visibilidade vertical - 2,7 m; visibilidade horizontal $-3 \mathrm{~m}$.

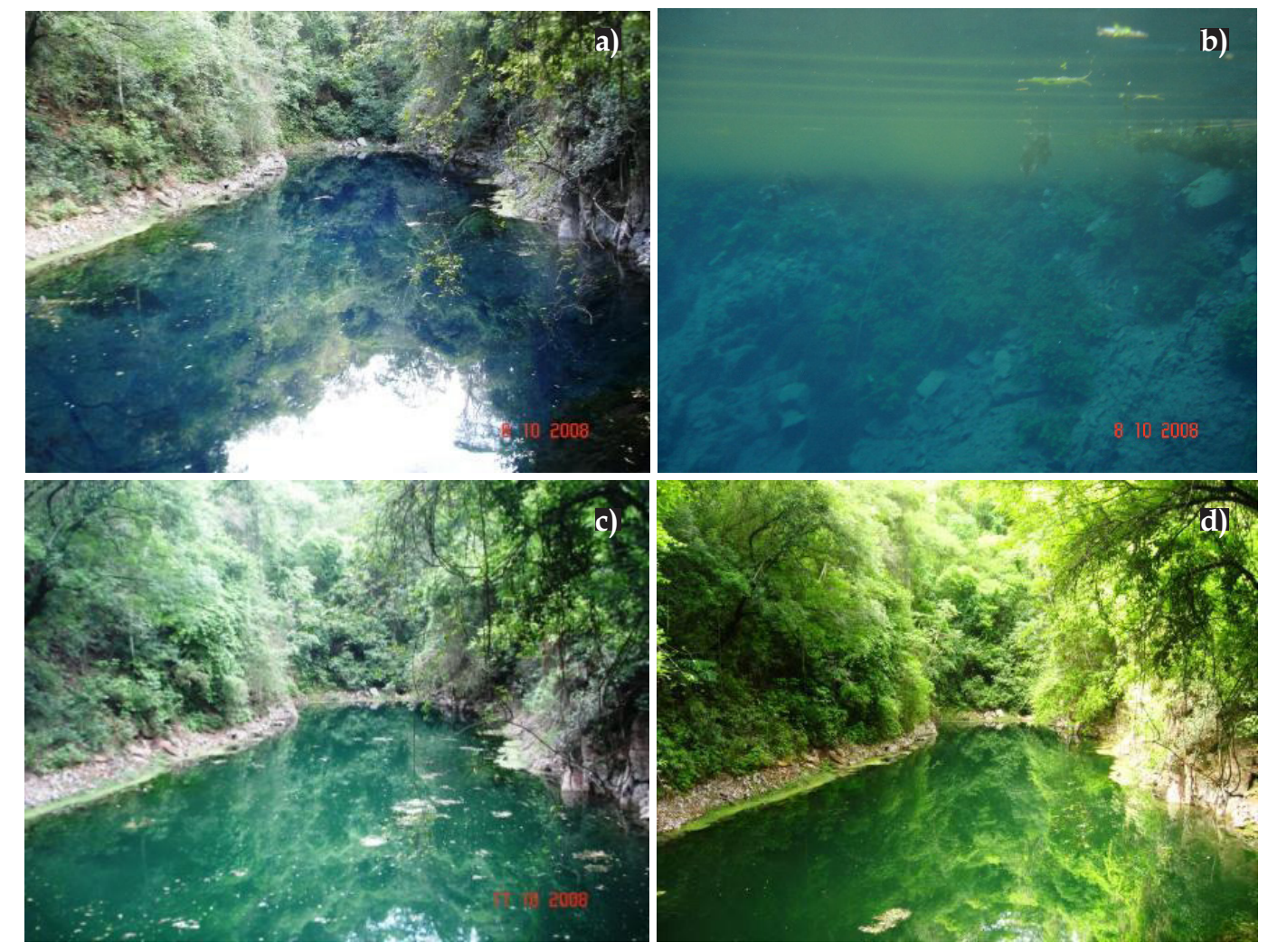

Fonte: arquivo pessoal dos autores.

Durante o período de eutrofização da Lagoa Misteriosa normalmente as águas superficiais são $0,5^{\circ} \mathrm{C}$ a $1^{\circ} \mathrm{C}$ mais quentes que as águas abaixo dos 2 metros de profundidade. Durante o período sem a presença do bloom de fitoplâncton elas permanecem constantes e iguais em $24^{\circ} \mathrm{C}$ ou as águas na superfície podem estar $0,5^{\circ} \mathrm{C}$ a $1^{\circ} \mathrm{C}$ mais frias do que as águas abaixo de 2 metros de profundidade (Fig. 7). Isto demonstra que a lagoa apresenta uma fraca estratificação térmica durante o verão, que, no entanto, não é mantida durante todo o períod o de floração e, portanto, não tem influência significativa no ciclo de floração.

A curva dos valores de $\mathrm{pH}$ acompanha a variação da pluviosidade, sendo mais alcalino nos períodos chuvosos. Este também pode constituir um fator sinergético já que várias algas proliferam bem em ambiente levemente básico (p.ex. Aulacoseira). A saturação do oxigênio dissolvido também apresentou maiores valores no período de chuvas com $108 \%$ em janeiro e menores valores no período de seca com $68 \%$ em abril e agosto. 
Figura 7. Variação de temperatura da água na superfície da Lagoa Misteriosa e abaixo de 2 metros de profundidade.

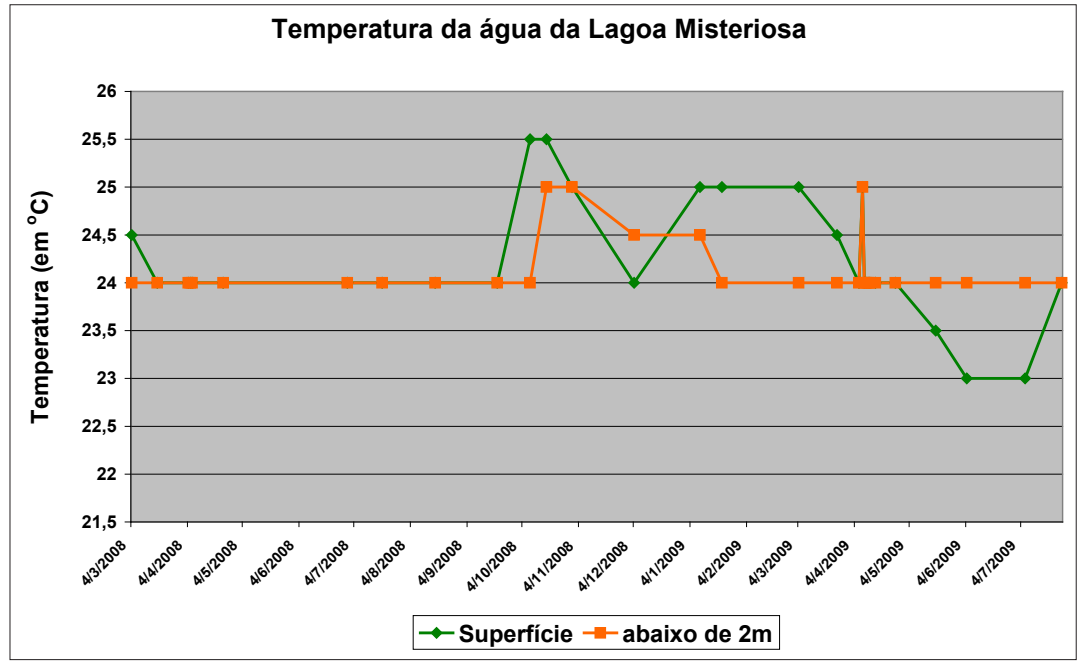

Fonte: os autores.

Os resultados demonstraram que a chuva parece ser a principal função de força que atua sobre as águas da Lagoa Misteriosa. Segundo Tundisi e Matsumura-Tundisi (2008) as funções de força, ou seja, a energia alóctone (externa) que direciona as mudanças físicas, químicas e biológicas, pode variar segundo o sistema, tais como flutuações hidrométricas e ventos para lagos amazônicos, radiação solar para os lagos do vale do rio Doce e tempo de residência, vento e precipitação para as represas. Na Lagoa Misteriosa, um local encaixado com alta densidade arbórea, o vento tem pouca influência, bem como a radiação solar, uma vez que a temperatura da água não sofre importantes variações temporais. Variações verticais de temperatura também não foram verificadas em medidas realizadas na coluna de água, descartando o fenômeno de estratificação que poderia ser uma função de força provocada pela radiação solar.

A concentração de oxigênio dissolvido na água da lagoa é bastante elevada, principalmente no período inicial da floração de algas (início da estação chuvosa) entre os meses de outubro e dezembro (Fig. 8). De janeiro em diante ocorre algumas oscilações, porém é possível notar uma tendência de queda até o final da floração.

Figura 8. Saturação do oxigênio dissolvido superficial (OD) na Lagoa Misteriosa.

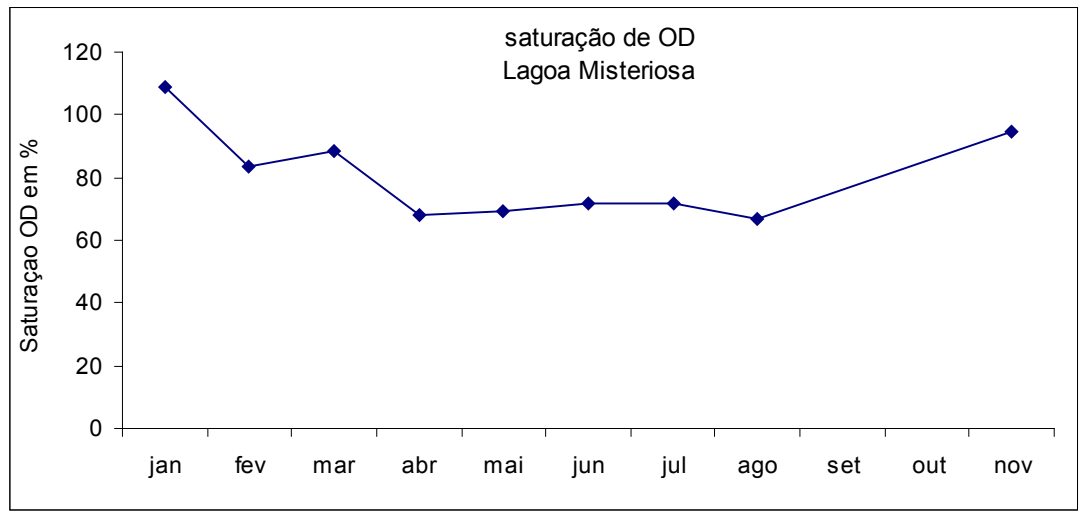

Fonte: Silva, 2009. 
A Figura 9 mostra o perfil de temperatura e oxigênio dissolvido na Lagoa Misteriosa em fevereiro de 2008. Provavelmente o aumento inicial de oxigênio dissolvido reflita o aumento da atividade de algas, realizando fotossíntese e liberando oxigênio na água. Com o aumento da profundidade ocorre um aumento na quantidade de matéria orgânica da lagoa e consequente aumento da demanda de oxigênio para oxidação e estabilização deste material e aumento da população de bactérias aeróbicas oxidantes desta matéria orgânica, com diminuição do oxigênio dissolvido.

Figura 9. Perfil de temperatura e oxigênio dissolvido na coluna de água da Lagoa Misteriosa em fevereiro de 2008.

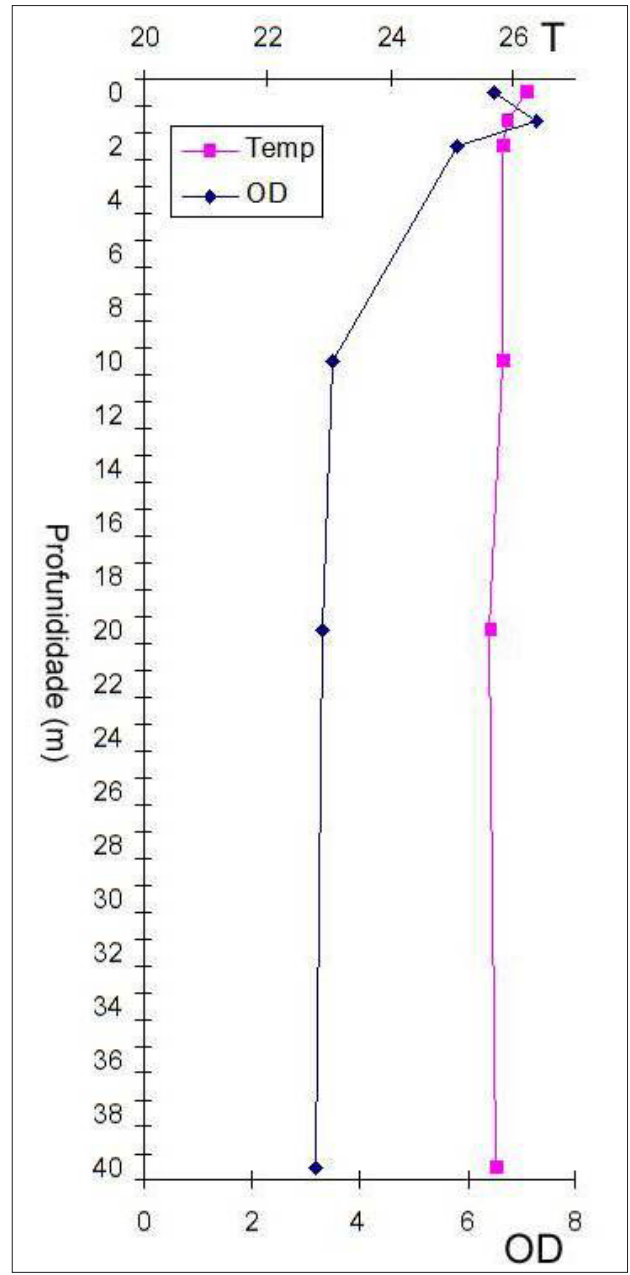

Fonte: Silva, 2009.

O aumento da matéria orgânica e da população de bactérias aeróbicas pode ser acompanhado através da análise dos parâmetros DBO e DQO (Fig. 10), que apresentam valores muito altos no verão, atingindo seus valores máximos entre os meses de fevereiro e maio (final do período de chuvas). Apesar da relativa diminuição do oxigênio dissolvido, o mesmo ainda mantém concentrações boas devido à atividade das algas que permanece alta até abril. Para exemplificar a boa concentração de oxigênio dissolvido nas águas da lagoa, a concentração deste parâmetro obtida no mês de dezembro de 2005 nunca foi 
atingida em nenhum ponto de monitoramento no Rio Formoso (um ambiente lótico pouco poluído) entre 1996 e 2001 ou 2003 (SEMA/IMAP, 2002; MATO GROSSO DO SUL, 2005).

Figura 10. Variação de parâmetros químicos da Lagoa Misteriosa no período de 2005 a 2009: oxigênio dissolvido (OD), Demanda Biológica de Oxigênio (DBO), Demanda Química de Oxigênio (DQO) e pH.

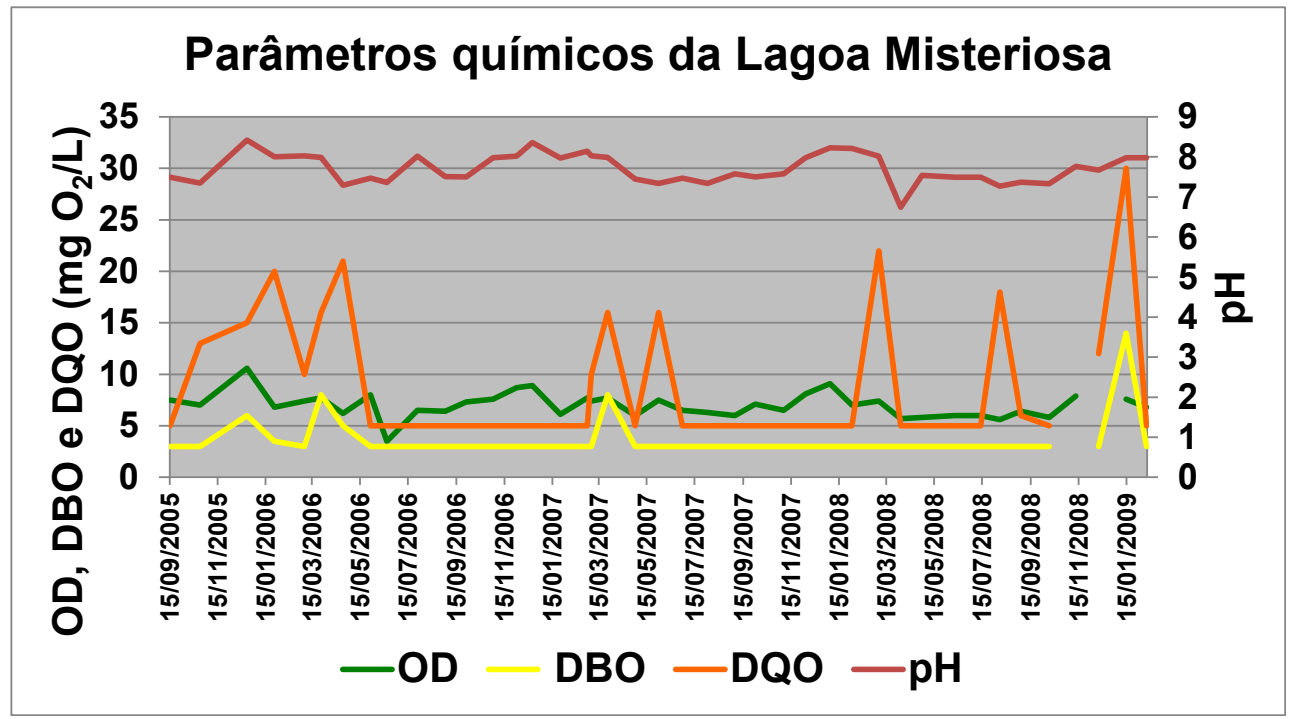

Nota: os valores de $\mathrm{pH}$ foram multiplicados por dois para adequação de escala. Fonte: os autores.

Poderia ser argumentado que, além da floração de algas, outro fator poderia contribuir para a turbidez da Lagoa, também relacionado com a grande concentração de fósforo na época das chuvas. Conforme Boggiani et al. (2002) o fosfato inibe a deposição do carbonato, e segundo Silva e Roche (2007) isto poderia estar diminuindo a transparência da água nesta época devido a maior quantidade de material em suspensão. Realmente é possível perceber uma relação entre o aumento da concentração de fósforo e de bicarbonato na água da Lagoa Misteriosa. Porém, esta grande quantidade de bicarbonato é esperada simplesmente pelo aumento das chuvas, com consequente aumento da dissolução do calcário e dolomito. Apesar de este fator colaborar com o aumento da turbidez da lagoa, sua contribuição deve ser pequena, pois em abril de 2006, no final do período das chuvas, quando a água da Lagoa Misteriosa ainda estava turva, a análise química mostra poucos sólidos em suspensão.

Portanto, é possível atribuir o turvamento da lagoa à floração, afirmação corroborada também pelos altos valores para clorofila-a (Fig. 11) e alta densidade das populações de fitoplâncton e zooplâncton entre outubro a março (Fig. 12), onde observa-se a relação entre clorofila e densidade fitoplanctônica com maiores valores na época de chuva e menores na seca; já na densidade de zooplâncton ocorreu um pico em agosto (seca) e uma tendência similar ao de fitoplâncton nos demais meses. Esta elevação em agosto, no entanto, está provavelmente relacionada a uma precipitação anormal no mês que acumulou mais de $100 \mathrm{ml}$ na área da lagoa, como já citado. 
Figura 11. Variação dos teores de clorofila-a da Lagoa Misteriosa, entre fevereiro de 2008 e janeiro de 2009.

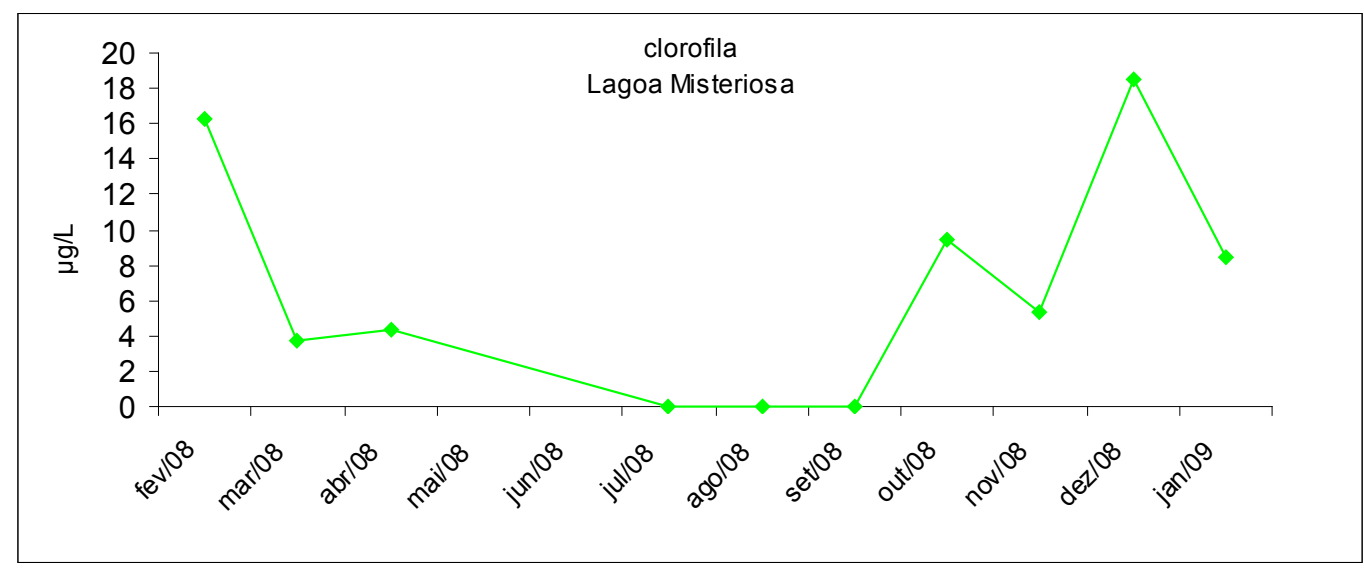

Fonte: os autores.

O fato da produção primária das águas estar relacionada apenas ao período de chuvas mostra que os nutrientes não retornam à coluna de água como ocorre em outros lagos naturais brasileiros (TUNDISI; MATSUMURA-TUNDISI; FUKUARA, 1997), onde ocorre entrada de nutrientes por escoamento superficial na época de chuvas e também provinda do hipolímnion quando ocorre a quebra de termoclina e consequente mistura das águas na época do inverno, com as temperaturas da superfície e fundo igualadas.

Figura 12. Densidade de fito e zooplâncton da Lagoa Misteriosa entre fevereiro de 2008 e janeiro de 2009.

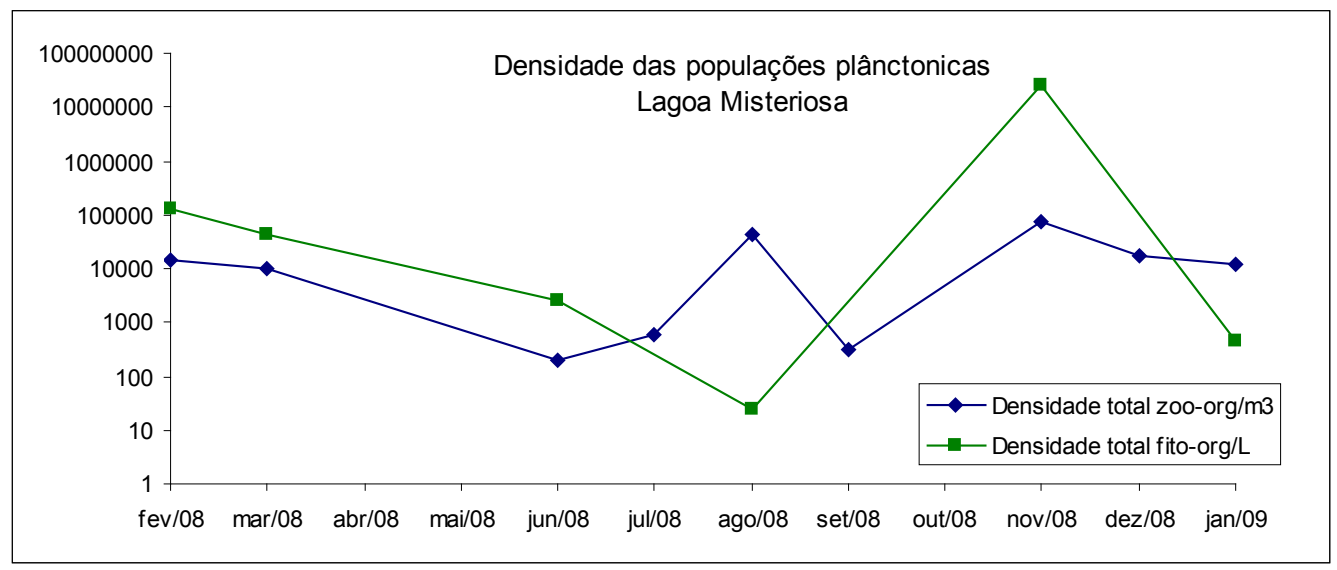

Fonte: os autores.

As Figuras 13 e 14 mostram a densidade de organismos do fitoplâncton e zooplâncton no período de fevereiro de 2008 a janeiro de 2009. Na comunidade fitoplanctônica, nos meses de maior densidade para o fitoplâncton, predominou Aulacoseira sp. em fevereiro e Coelastrum sp. em novembro. Em análise anterior realizada pela professora Liliane Rodrigues (dados não publicados), em material coletado em 15 de dezembro de 2006, foi constatada basicamente a presença Aulacoseira granulata var. angustissima e Tetrastrum triangulare no material planctônico, que correspondeu a aproximadamente $95 \%$ da densidade total da amostra (FERNANDES; SCHEFFLER, 2009). Em abril de 2006, no final da estação chuvosa, 
os táxons de fitoplâncton mais comuns foram os gêneros Peridinium, Oscillatoria e Aulacoseira (SILVA; ROCHE, 2007). A presença rotineira de Aulacoseira provavelmente se deve a sua tolerância a alta turbidez e baixa alcalinidade ( $\mathrm{pH}$ entre 7 e 8,5). Portanto, o aumento da turbidez da água deve ser devido principalmente ao bloom destas espécies, que podem não ocorrer alternadamente durante todo o ano: Aulacoseira sp., Tetrastrum sp., Peridinium sp., Oscillatoria sp., Coleastrum sp, Closterium sp. e Euastrum sp.

Figura 13.Composição de espécies no fitoplâncton na Lagoa Misteriosa entre fevereiro de 2008 e janeiro de 2009.

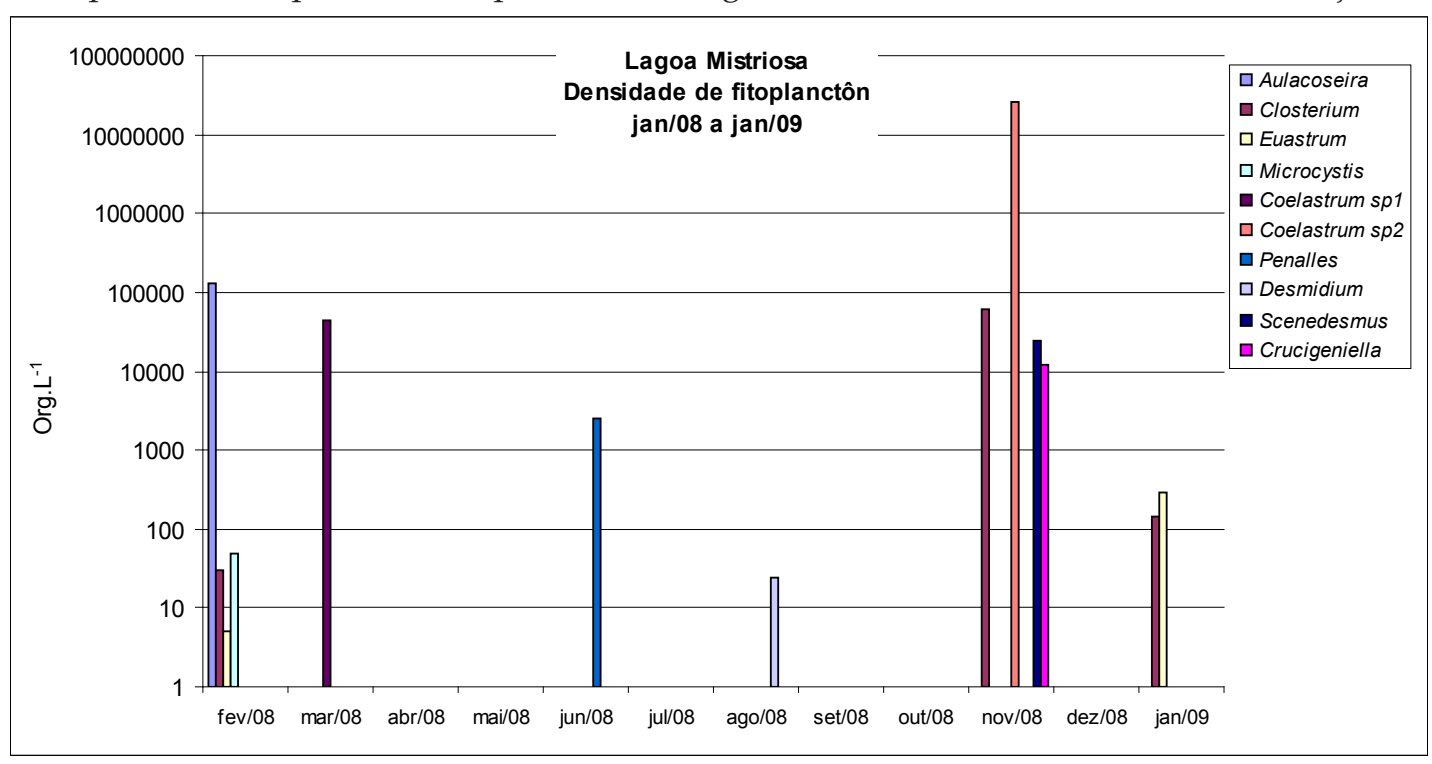

Fonte: os autores.

A população de zooplâncton apresentou, com maior densidade em fevereiro, a espécie Keratella tropica; em agosto Ascomorpha sp., e em novembro Trichodina sp. (entretanto neste mês houve também grandes densidades de Hexarthra sp, Anaueropsis sp, Polyarthra sp e Keratella tropica). No trabalho de Silva e Roche (2007) o zooplâncton também foi representado somente por rotíferos, sendo mais abundantes Trichocerca similis, Keratella americana e Polyarthra vulgaris, com aumento da densidade nos meses chuvosos acompanhando da maior disponibilidade de recursos e alimentos. Os rotíferos são organismos de ciclo de vida muito curto, entre uma semana e um mês. Tundisi e Matsumura-Tundisi (1994) apontam que ambientes tropicais dominados por Rotífera são ambientes instáveis e que sofrem pulsos frequentes de perturbação, inviabilizando organismos de ciclo de vida maiores, tais como artrópodes Cladocera e Copepoda. Na Lagoa Misteriosa foram registradas apenas formas jovens de Copepoda (náuplios), que se alimentam de seu próprio saco vitelino e podem não estar completando o ciclo para chegar a fase adulta. Silva (2009), além de formas adultas de Copepoda, também não observou seus principais predadores, como hidrozoários, o que reforça a impossibilidade da conclusão do ciclo de vida devido ao ambiente instável. 
Figura 14. Composição de espécies no zooplâncton na Lagoa Misteriosa entre fevereiro de 2008 e janeiro de 2009.

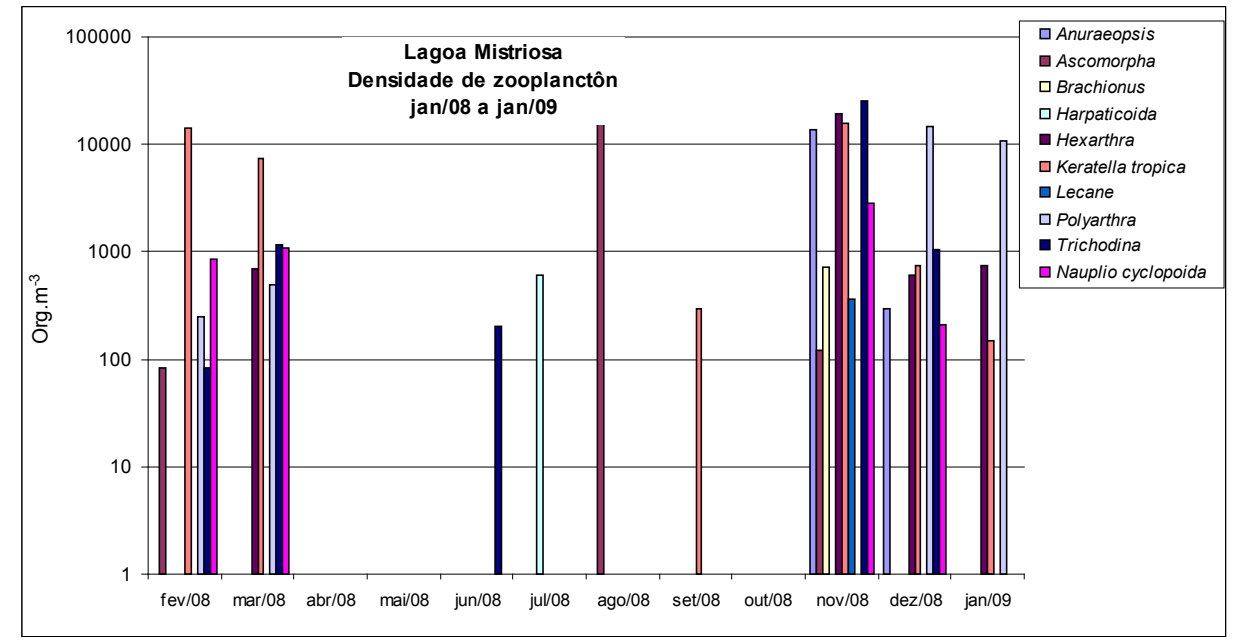

Fonte: os autores.

Enquanto o surgimento da floração de algas pode ser facilmente explicado, para o seu término duas hipóteses podem ser apontadas. Uma primeira possibilidade é a formação de complexos com os carbonatos que sequestram e imobilizam o fósforo, precipitado nas grandes profundidades do lago. No entanto, isto não explicaria o término da floração de algas sempre no mês de abril (ao menos nos anos acompanhados), principalmente em anos que apresentam ainda grande quantidade de chuvas em maio, como em 2006 e 2008. Parece que este ciclo é um pouco mais complexo e o final da floração de algas provavelmente está relacionado mais com a chegada da primeira frente fria mais intensa do ano, e consequente queda brusca de temperatura. A queda da temperatura ambiente resfria as águas da superfície do lago gerando uma diferença de temperatura entre a superfície e o fundo (termoclina), provocando provavelmente um processo de convecção térmica, que leva tanto os microorganismos quanto os nutrientes para o fundo. Isto pode ser bem evidenciado em 2005, quando a lagoa se apresentava turva e, após a chegada de frente fria intensa no dia 25 de abril, as águas tornaram-se extremamente cristalinas em um intervalo de apenas dois dias. Em 2006, a floração cessou rapidamente após a chegada da frente fria nos dias 15 e 16 de abril. Neste mesmo mês ocorreu nova chuva (dia 22), porém as águas da lagoa permaneceram cristalinas, evidenciando portanto, que as quedas bruscas de temperatura e não a ausência de chuvas seriam o principal fator que leva ao desaparecimento deste fenômeno. Em abril de 2007 o desaparecimento da floração foi mais gradual (entre os dias 9 e 20). Neste ano não ocorreu uma frente fria bem marcada, apenas leves baixas de temperatura nos dias 9, 10 e 11 de abril, que provocaram o desaparecimento da floração de algas, mesmo ocorrendo nova chuva no mês (dia 23). Em 2008 a floração chegou ao fim entre os dias 04 a 06 de abril, após avanço de forte frente fria no início de abril, com brusca queda de temperatura, sendo possível acompanhar a gradual mudança da coloração de verde-musgo intenso para um azulado cristalino (Fig. 15). 
Figura 15. (a) Lagoa Misteriosa em 18/03/2008; (b) Lagoa Misteriosa em 04/04/2008; (c) Lagoa Misteriosa em 05/04/2008; (d) Lagoa Misteriosa em 23/04/2008.
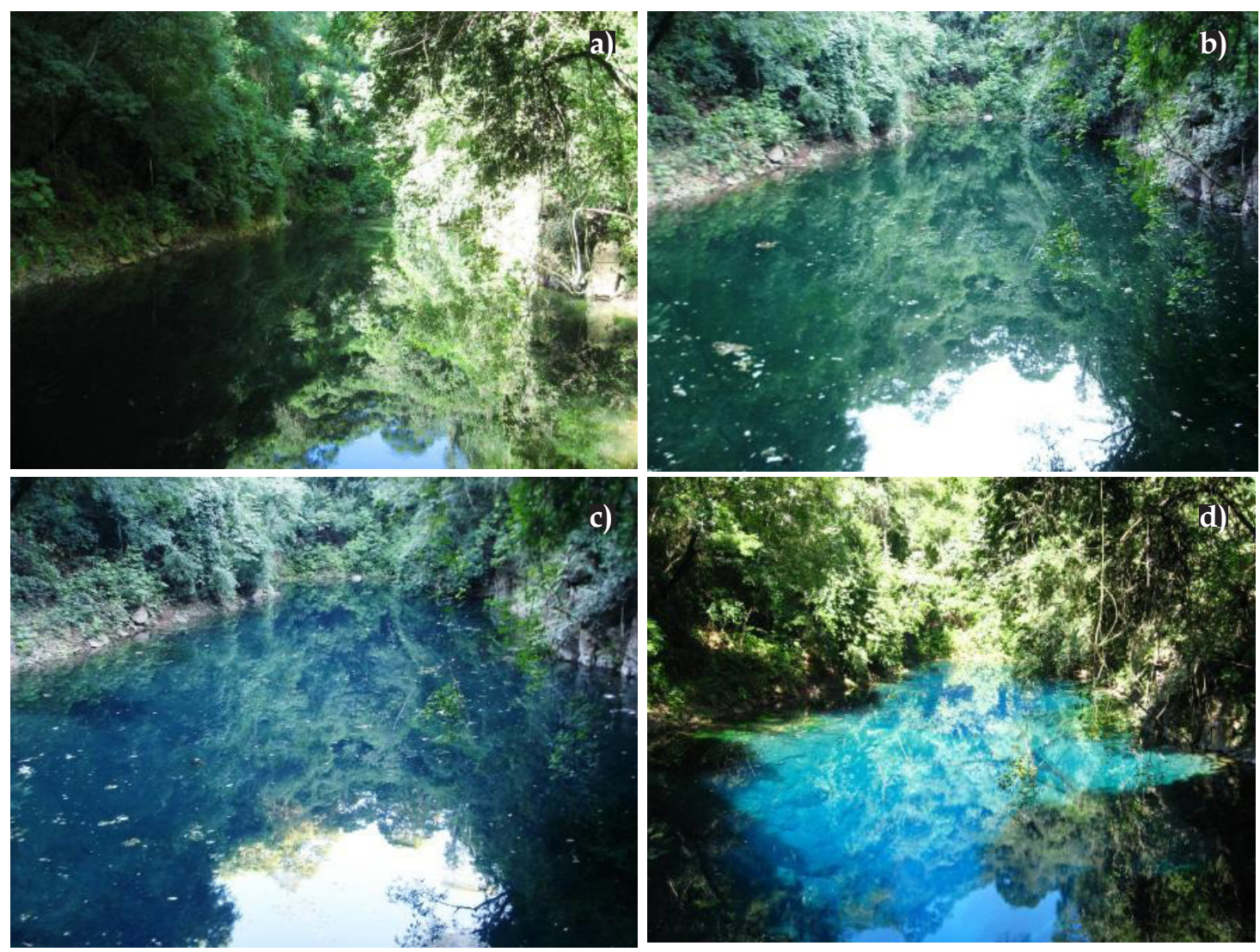

Fonte: arquivo pessoal dos autores.

Para aprimorar o entendimento deste fenômeno durante o ano de 2008 foi realizado um acompanhamento detalhado das variáveis climáticas locais (temperatura do ar, umidade relativa do ar, pressão atmosférica, radiação solar e precipitação) até o clareamento das águas da lagoa. Para isso os dados utilizados foram obtidos da Estação Jardim (31953) / AGROMET da plataforma de coleta de dados meteorológicos, hidrológicos e ambientais do CPTEC/INPE. Esta análise permitiu confirmar a presença de uma frente fria que avançou sobre o Estado do Mato Grosso do Sul e ocasionou uma grande queda de temperatura a partir do dia 04 de abril, caracterizada como a mais intensa do ano até a data. As temperaturas mais frias do dia oscilavam entre 20 e $23^{\circ} \mathrm{C}$ nas madrugadas entre os dias 26 de março a 03 de abril, caindo bruscamente para $12,5^{\circ} \mathrm{C}$ e $14^{\circ} \mathrm{C}$ nas madrugadas do dia 04 e 06 de abril, respectivamente. A análise visual de imagens de satélite GOES, entre os dias 30 de março de 2008 e 06 de abril de 2008, também permitiu visualizar o período de avanço e domínio desta massa de ar frio sobre o estado, e posteriormente sua tropicalização. A Lagoa manteve-se azul cristalina após entrada desta frente fria, apesar das chuvas dos dias 13, 18 e 29 de abril. 


\section{CONSIDERAÇÕES FINAIS}

Os resultados mostram que a pluviosidade é a principal função de força que atua sobre as águas da Lagoa Misteriosa. O bloom fitoplanctônico se inicia com as primeiras chuvas no final de setembro ou início de outubro, quando a precipitação arrasta o material da superfície de entorno da lagoa por escoamento superficial, diminuindo a transparência da água pelo aumento do material em suspensão, além de carrear nutrientes como fósforo e nitrogênio. A produção primária das águas da Lagoa Misteriosa, realizada pelo fitoplâncton, aumenta neste no período de chuvas, verificado pelos valores de clorofila e densidade fitoplanctônica.

A Lagoa Misteriosa, sem estratificação térmica, logo sem barreira física para impedir o retorno dos nutrientes para a superfície, tem na profundidade e na formação de complexos com os carbonatos os principais fatores que sequestram e imobilizam o fósforo. Para o retorno do fósforo à superfície seria também necessário a anoxia nas regiões profundas, o que não foi verificado no período amostrado. Os resultados apontam para uma eficiência no aproveitamento do fósforo livre na coluna de água, num ambiente fósforo limitante, imobilizado nas moléculas orgânicas de organismos planctônicos e material alóctone, refletidos nos valores de fósforo total.

As densidades de fitoplâncton e zooplâncton mostram um padrão clássico onde as condições favoráveis promovem o desenvolvimento das comunidades herbívoras e detritívoras e o aumento destas comunidades leva ao declínio dos produtores (KREBS, 1994). Estes, além da pressão por predação, sofrem também limitação por nutrientes, especialmente fósforo.

A entrada da primeira frente fria do ano, capaz de baixar significativamente a temperatura, que ocorreu sempre no mês de abril dos anos acompanhados, controla o final do ciclo de floração de algas e alta densidade zooplanctônica. A queda repentina da temperatura provavelmente provoca correntes de convecção que levam para o fundo da lagoa tanto os nutrientes, como os microorganismos, e impede que os mesmos permaneçam próximos a superfície, mesmo com a ocorrência de novas chuvas posteriores.

Variáveis adicionais que podem influenciar as comunidades planctônicas devem ser mais analisadas para responder as questões do funcionamento ecológico da Lagoa Misteriosa, como a influência das macrófitas e das fases jovens dos peixes sobre as comunidades planctônicas.

Finalmente, talvez o aumento da incidência anual da floração algal a partir da década de 1980, como relatado por moradores, possa estar relacionado à implantação de pastagens exóticas e intensificação no uso de fertilizantes nas áreas do entorno.

\section{AGRADECIMENTOS}

Agradecemos ao apoio de Eduardo Folley Coelho, proprietário das Fazendas Lagoa Misteriosa e Cabeceira do Prata e Anézia Bastos e Jorge Bastos, proprietários da Fazenda 
Santa Maria pelo apoio à realização dos estudos na Lagoa Misteriosa e seu entorno. Agradecemos também à Hamilton de Menezes Fernandes pelo auxílio na coleta dos dados físico-químicos.

\section{REFERÊNCIAS}

AMARAL FILHO, Zebino Pacheco do. Macrozoneamento Geoambiental do Estado de Mato Grosso do Sul. Campo Grande: Governo do Estado de Mato Grosso do Sul, 1989. 140p. (Relatório do Convênio de Cooperação Técnico-Científica da Fundação Instituto Brasileiro de Geografia e Estatística-IBGE e o Estado de Mato Grosso do Sul).

BARROCO NETO, Jose L. Topografia sub-aquática da cavidade natural Lagoa Misteriosa. In: FERNANDES, Hamilton de Menezes; SCHEFFLER, Sandro Marcelo (coords.). Plano de Manejo Espeleológico da Lagoa Misteriosa, Jardim/MS. Jardim: Empreendimentos Turísticos Rio da Prata Ltda., 2009. v. 5. Apêndice I.

BOGGIANI, Paulo César; COIMBRA, Armando Márcio; GESICKI, Ana Lúcia Desenzi et al. (eds.). Sítios Geológicos e Paleontológicos do Brasil. Brasília: DNPM/CPRM/SIGEP, 2002. p. 249-259.

COELHO, Luiza Spengler. Classificação Trófica da Lagoa Misteriosa. In: FERNANDES, Hamilton de Menezes; SCHEFFLER, Sandro Marcelo (coords.). Plano de Manejo Espeleológico da Lagoa Misteriosa, Jardim/MS. Jardim: Empreendimentos Turísticos Rio da Prata Ltda., 2009. v. 3. p. 222-225.

CORDEIRO, Lívia Medeiros; BORGHEZAN, Rodrigo, TRAJANO, Eleonora. Biodiversidade subterrânea na área cárstica da Serra da Bodoquena, bacia do Rio Paraguai, Estado do Mato Grosso do Sul, Sudoeste do Brasil. Biota Neotropica, v. 14, n. 3, e201400114, 2014. Doi.org/10.1590/1676-06032014011414.

ESTEVES, Francisco de Assis. Fundamentos de Limnologia. 2.ed. Rio de Janeiro: Interciência/FINEP, 1998.

FERNANDES, Hamilton de Menezes; SCHEFFLER, Sandro Marcelo. Plano de Manejo Espeleológico da Lagoa Misteriosa. Jardim: Empreendimentos Turísticos Rio da Prata Ltda., 2009. 5v. 353p.

KLEEREKOPER, Herman. Introdução ao Estudo da Limnologia. 2.ed. Porto Alegre: Ed. UFRGS, 1944.

KREBS, Charles. J. Ecology: The experimental Analysis of Distribution and Abundance. 6.ed. Vancouver: University of British Columbia, 1994. 816p.

LINO, Clayton Ferreira; BOGGIANI, Paulo Cesar; CORTESÃO, Judith et al. Projeto Grutas de Bonito: diretrizes para um plano de manejo turístico. Campo Grande: SPHAN/MS-TUR, 1984. 212p. (Relatório).

MATO GROSSO DO SUL. Relatório de Qualidade das Águas Superficiais da bacia do Alto Paraguai, MS, 2003. Campo Grande: Secretaria de Estado de meio Ambiente/ Instituto de Meio Ambiente Pantanal. Gerência de Recursos Hídricos, 2005. 127 p. (Projeto GEF Pantanal/Alto Paraguai - implementação de Práticas de Gerenciamento Integrado de Bacia Hidrográfica para o Pantanal e Alto Paraguai (ANA/GEF/ PNUMA/OEA). Subprojeto 1.6/MS - Gerenciamento de Recursos Hídricos nas Vizinhanças da Cidade de Corumbá - MS).

MATSUMURA-TUNDISI, Takako; TUNDISI, José Galizia. Limnology of a warm monomictic lake at rio Doce Forest Park (Lake Dom Helvecio, MG, Eastern Brazil). In: TUNDISI J.G.; BICUDO, C.E.M.; MATSUMURA-TUNDISI T. (org). Limnology in Brazil. Rio de Janeiro: Academia Brasileira de Ciências/ SBL, 1995. p. 245-256.

MENDES, Carlos André B.; DIAS, Felipe Augusto; LANGE, Maria Bernadete Ribas et al. Bacia Hidrográfica do Rio Miranda: estado da arte. Campo Grande: UCDB, 2004. 177p.

OLIVEIRA, Gilberto Menezes de. Lagoa Misteriosa. In: AULER, Augusto; RUBBIOLI, Ézio; BRANDI, Roberto (eds.). As grandes cavernas do Brasil. Belo Horizonte: Grupo Bambuí de Pesquisas Espeleológicas, 2001. 228p.

RAVEN, Peter; EVERT, Ray; EICHHORN, Susan. Biologia Vegetal. 6.ed. Rio de Janeiro: Guanabara Koogan, 2001. 
SALLUN FILHO, William; KARMANN, Ivo. Geomorphological map of the Serra da Bodoquena karst, West-Central Brazil. Journal of maps, p. 282-295, 2007a.

; ___ Dolinas em arenitos da Bacia do Paraná: evidências de carste subjacente em Jardim (MS) e Ponta Grossa (PR). Revista Brasileira de Geociências, v.37, n.3, p. 551-564, 2007b.

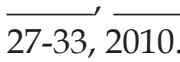
; LOBO, Heros Augusto Santos. Cavernas na Serra da Bodoquena. O Carste, v. 22, n. 2, p.

SBE - Sociedade Brasileira de Espeleologia. Lista dos maiores desníveis da Sociedade Brasileira de Espeleologia. 2019. Disponível em: http://www.sbe.com.br/cavernas_maiores.asp. Acessado em: 04 de setembro.

SCHEFFLER, Sandro Marcelo. Geologia. In: FERNANDES, Hamilton de Menezes; SCHEFFLER, Sandro Marcelo (coords.). Plano de Manejo Espeleológico da Lagoa Misteriosa, Jardim/MS. Jardim: Empreendimentos Turísticos Rio da Prata Ltda., 2009a. v. 3, p. 77-111.

Considerações sobre o carste na área da cavidade natural Lagoa Misteriosa (Jardim, Mato Grosso do Sul) In: ENCONTRO BRASILEIRO DE ESTUDOS DO CARSTE. 3. 2009. São Carlos. Anais... São Carlos: UFSC, 2009. v.1. p.75-82.

SEMA/IMAP - Secretaria de Estado de Meio Ambiente e Recursos Hídricos/Instituto de Meio Ambiente Pantanal. Bacia Hidrográfica do Rio Formoso: qualidade das águas. Campo Grande: Gerência de Recursos Hídricos de Mato Grosso do Sul, 2002. 66p. (Projeto Implementação de Práticas de Gerenciamento Integrado de Bacia Hidrográfica para o Pantanal e Bacia do Alto Paraguai, ANA/GEF/PNUMA/OEA).

SILVA, William Marcos. Aspectos limnológicos da Lagoa Misteriosa In: FERNANDES, Hamilton de Menezes; SCHEFFLER, Sandro Marcelo (coords.). Plano de Manejo Espeleológico da Lagoa Misteriosa, Jardim/MS. Jardim: Empreendimentos Turísticos Rio da Prata Ltda., 2009. v. 3, p. 195-202.

; ROCHE, Kennedy Francis. Occurrence of the freshwater jellyish Craspedacusta sowerbii (Lankester, 1880) (Hydrozoa, Limnomedusae) in a calcareous lake in Mato Grosso do Sul, Brazil. Biota Neotropica, v. 7, n. 1, p.173-176, 2007.

TUNDISI, Jose Galizia.; MATSUMURA-TUNDISI, Takako. Plankton diversity in a warm monomictic lake (Dom Helvécio, Minas Gerais) and a polymictic reservoir (Barra Bonita): a comparative analysis of the intermediate disturbance hypothesis. Anais da Academia Brasileira de Ciências, v.66, n.1, p.15-28, 1994.

FUKUARA, Haruo et al. Limnology of Fifteen Lakes. In: SAIJO, Yatsuka; TUNDISI, José Galizia. (eds.). Limnological studies on the Rio Doce Valley Lakes, Brazil. Rio de Janeiro: Academia Brasileira de Ciências/ USP, 1997. p. 409-440.

Limnologia. São Paulo: Oficina de Textos, 2008.

Data de submissão: 16/ mar./ 2019

Data de aceite: 08/ ago./ 2019 